\title{
Analysis of polygonal cracking patterns in chloride-bearing terrains on Mars: Indicators of ancient playa settings
}

\author{
M. R. El-Maarry, ${ }^{1}$ A. Pommerol, ${ }^{1}$ and N. Thomas ${ }^{1}$ \\ Received 14 June 2013; revised 29 September 2013; accepted 8 October 2013; published 4 November 2013.
}

[1] The ancient southern highlands on Mars ( $\sim 3.5 \mathrm{Gyr}$ old) contain $>600$ regions that display spectral evidence in the infrared for the presence of chloride-bearing materials. Many of these locations were previously reported to display polygonal cracking patterns. We studied more than 80 of the chloride-bearing terrains using high-resolution $(0.25-0.5 \mathrm{~m} / \mathrm{pixel})$ images, as well as near-infrared spectral data, to characterize the surface textures and the associated cracking patterns and mineralogies. Our study indicates that $\sim 75 \%$ of the studied locations display polygonal cracks that resemble desiccation cracks, while some resemble salt expansion/thrust polygons. Furthermore, we detect, spectrally, the presence of smectites in association with $\sim 30 \%$ of the studied fractured terrains. We note that smectites are a special class of swelling clay minerals that can induce formation of large desiccation cracks. As such, we suggest that the cracking patterns are indicative of the presence of smectite phyllosilicates even in the absence of spectral confirmation. Our results suggest that many chloride-bearing terrains have a lacustrine origin and a geologic setting similar to playas on Earth. Such locations would have contained ephemeral lakes that may have undergone repeated cycles of desiccation and recharging by a near-surface fluctuating water table in order to account for the salt-phyllosilicates associations. These results have notable implications for the ancient hydrology of Mars. We propose that the morphologies and sizes of the polygonal cracks can be used as paleoenvironmental, as well as lithological, indicators that could be helpful in planning future missions.

Citation: El-Maarry, M. R., A. Pommerol, and N. Thomas (2013), Analysis of polygonal cracking patterns in chloride-bearing terrains on Mars: Indicators of ancient playa settings, J. Geophys. Res. Planets, 118, 2263-2278, doi:10.1002/2013JE004463.

\section{Introduction}

[2] The geological record of Mars suggests that it has been cold and dry for most of the past $3 \mathrm{Gyr}$, except for regionally localized transient events [e.g., Carr and Head, 2010, and references therein]. However, significant debate remains regarding the first billion years that followed the planet's formation of a solid crust [e.g., Fairén, 2010, and references therein], which generally corresponds to the Noachian period [Tanaka, 1986; Hartmann and Neukum, 2001]. The Noachian crust records various lines of evidence that suggest that there may have been a more globally active hydrological cycle and potentially a warmer climate. This evidence includes the presence of valley networks [e.g., Carr, 1995, 1996; Howard et al., 2005; Fassett and Head, 2008; Hynek et al., 2010; Irwin et al., 2011], explosive

Additional supporting information may be found in the online version of this article.

${ }^{1}$ Physikalisches Institut, Bern Universtät, Berne, Switzerland.

Corresponding author: M. R. El-Maarry, Sidlerstrasse, 5, 3012, Berne, Switzerland. (mohamed.elmaarry@space.unibe.ch)

(C)2013. American Geophysical Union. All Rights Reserved. 2169-9097/13/10.1002/2013JE004463 volcanism, which involves the interaction and mixing of magma with near-surface volatiles [e.g., Mouginis-Mark et al., 1982; Mouginis-Mark, 1985; Greeley and Crown, 1990; Robinson et al., 1993], in addition to the surface mineralogical diversity and wide extent of clay minerals as well as other hydrous phyllosilicates [e.g., Poulet et al., 2005; Bibring et al., 2006; Mustard et al., 2008; Murchie et al., 2009; Ehlmann et al., 2009, 2011; Wray et al., 2009; Carter et al., 2010], and salts such as carbonates [Ehlmann et al., 2008], sulfates [e.g., Langevin et al., 2005; Mangold et al., 2008; Murchie et al., 2009], and chlorides [Osterloo et al., 2008, 2010].

[3] Osterloo et al. [2008, 2010] identified and mapped many spectrally distinct terrains within the Noachian crust, which they interpreted to be chloride-bearing terrains based on the materials' thermal infrared spectral properties. Follow-up studies have supported the initial interpretation using laboratory near-infrared (NIR) and site-specific studies on the Martian surface [e.g., Glotch et al., 2010; Jensen and Glotch, 2011; Glotch et al., 2013]. In addition, Osterloo et al. [2008, 2010] reported that the chloride-bearing terrains displayed cracking patterns of variable scales, which they interpreted to be potential desiccation cracks caused by the drying out of lakes or brines that ultimately led to the deposition of the chlorides. 
EL-MAARRY ET AL.: CRACKING IN CHLORIDE-BEARING TERRAINS
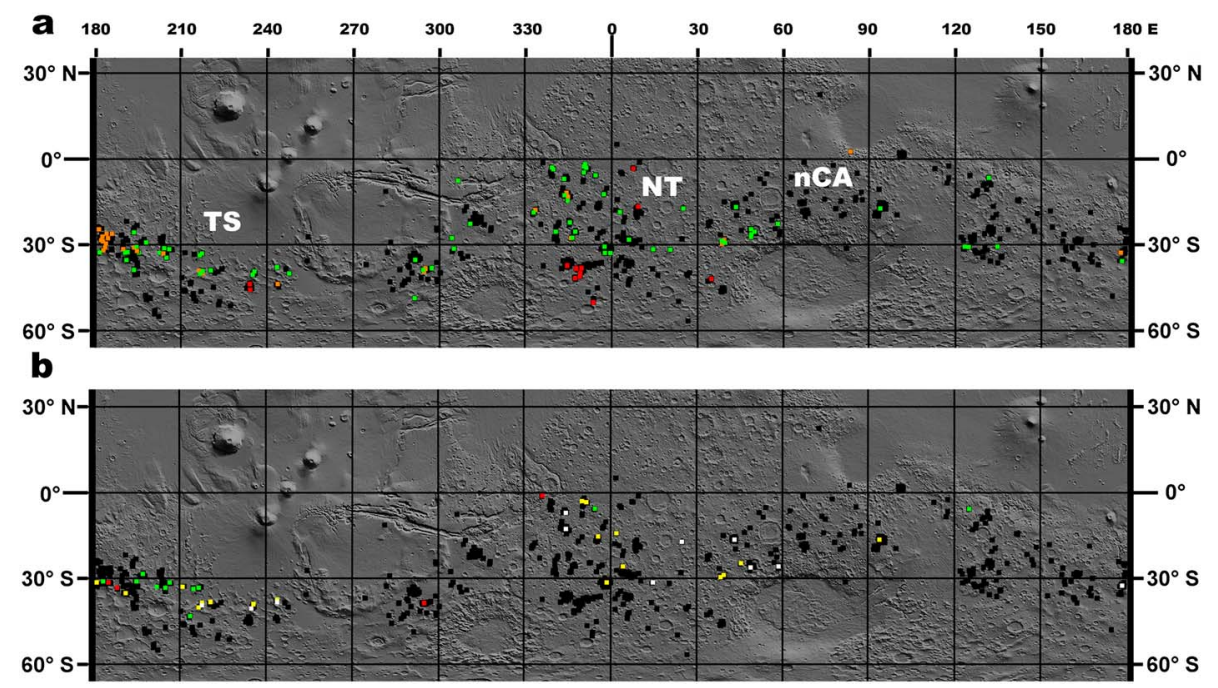

Figure 1. (a) Midlatitudes Mars Orbiter Laser Altimeter shaded relief map showing the locations of the chloride-bearing terrains (642 locations) on Mars as identified by Osterloo et al. [2010] (black squares). Colored squares generally represent the locations that have been investigated in this study using HiRISE images (86 regions). Green squares correspond to the locations with confirmed cracking patterns within or directly adjacent to the chloride-bearing terrains (68 regions), which roughly corresponds to $\sim 75 \%$ of the regions imaged by HiRISE. Red squares represent areas where no cracking has been observed (16 regions). Orange squares represent locations with putative cracking patterns (27 regions), which are mostly inferred from geological context and may not necessarily have direct HiRISE cover (see Table S1 in the supporting information for details). The main bulk of locations displaying polygonal cracking is grouped into three provinces: Terra Sirenum (TS), Noachis Terra (NT), and northern circum-Argyre (nCA). (b) Similar map showing the fractured terrains that have been investigated spectrally using CRISM (42 locations, section 3.2). These terrains are classified into three classes: (1) Fractured chloride-bearing materials with no clay signature (yellow), (2) Non-fractured chloride-bearing mantles/crusts overlying fractured smectites (green), and (3) fractured chloridebearing materials and fractured smectites in close proximity (red). Some locations lack relevant mineralogical information such as a red slope or hydrated/mafic minerals (white).

[4] We investigate the chloride-bearing terrains using high spatial resolution images, mainly from the High Resolution Imaging Science Experiment (HiRISE) [McEwen et al., 2007], in order to assess fully the occurrence of polygonal cracks, as well as the possible phyllosilicates-chlorides relationship that previous authors have noted (see section 2). We use imagery from HiRISE to characterize the meter-scale morphology of the cracks as well as their geological and stratigraphical setting in relation to phyllosilicate-bearing deposits. We identify and map the phyllosilicate spatial extent and association with the chloride-bearing materials using spectral cubes from the Compact Reconnaissance Imaging Spectrometer for Mars (CRISM) [Murchie et al., 2007]. This work is part of an ongoing research theme regarding non-periglacial polygonal cracking patterns on Mars that are potentially of desiccation origin using mapping, analytical and numerical simulations, terrestrial analog field studies, and experiments on analog simulants [El Maarry et al., 2010, 2012a, 2012b].

\section{Overview of Previous Studies}

[5] Osterloo et al. [2008] identified and mapped a spectrally distinct compositional unit using data from the Mars Odyssey Thermal Imaging System [Christensen et al.,
2004] and the Mars Global Surveyor Thermal Emission Spectrometer [Christensen et al., 2001]. These materials are scattered within the southern highlands yet significantly concentrated in Terra Sirenum (Figure 1). They are composed of light-toned materials that are occasionally polygonally fractured (Figure 2) and lie within topographical depressions in typically low-albedo terrains of Noachian or Early Hesperian age. Their morphologies and thermal inertia indicate that they are relatively consolidated materials. The combination of these attributes led Osterloo et al. [2008] to conclude that these units were chloride-bearing materials that could have formed by precipitation from evaporating surfaces, such as saline lakes and groundwater/hydrothermal brines (as volcanic sublimates), or by direct efflorescence [Osterloo et al., 2008].

[6] Osterloo et al. [2010] expanded the data set of these terrains from $\sim 200$ locations to 642 locations (Figure 1). Their investigation included a survey of how many deposits displayed a polygonally fractured surface using the HiRISE imagery available at the time. Their work also included the analysis of global and regional mineralogy as well as correlations with globally mapped properties and features such as dust content, surface age, thermal inertia, valley network density, and global elemental maps from the Gamma-ray spectrometer [Boynton et al., 2007]. Jensen and Glotch [2011] and Glotch et al. [2013] investigated the NIR spectral 


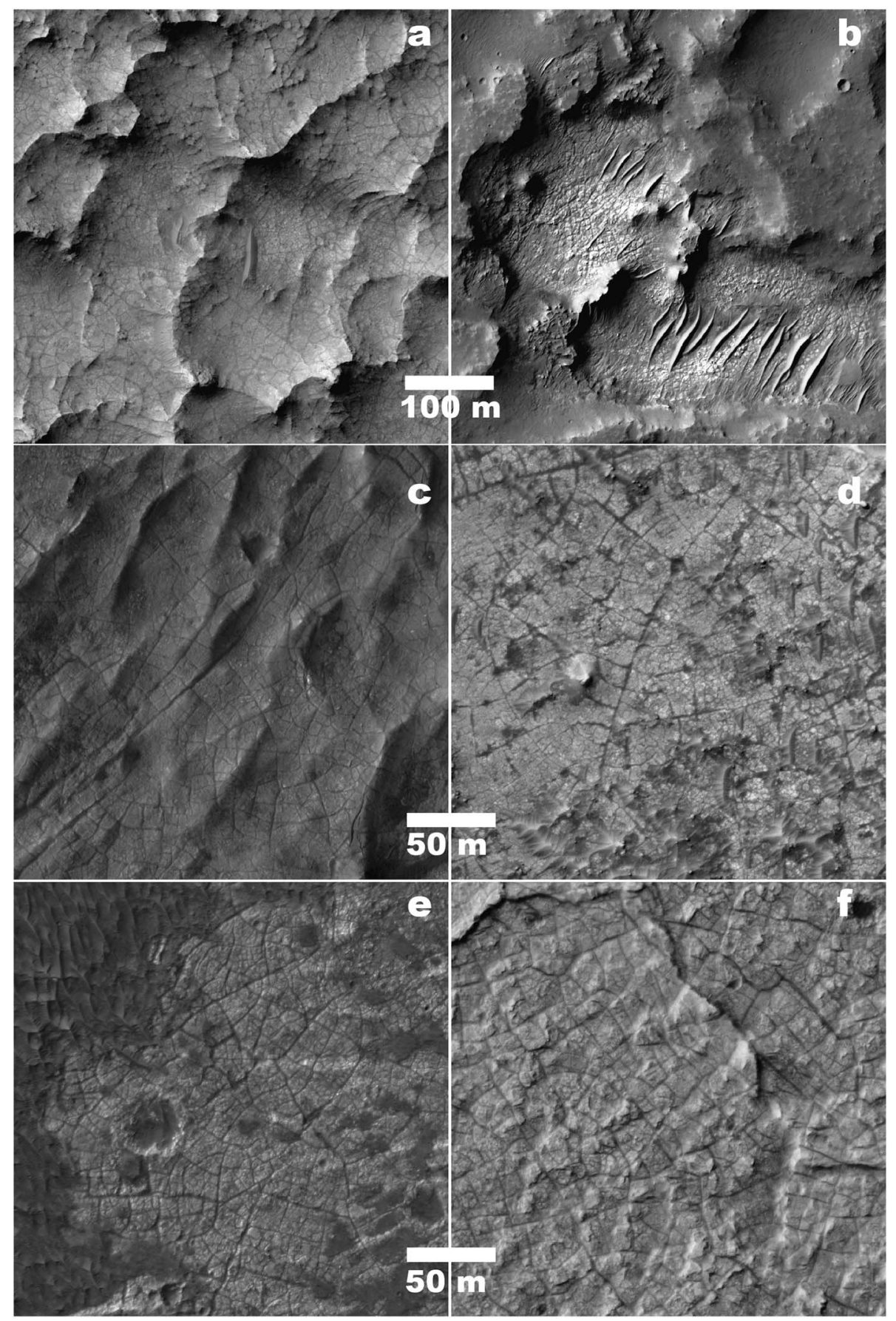

Figure 2. Typical polygonal cracks associated with chloride-bearing deposits as seen using the HiRISE camera. The cracks are generally $1-2 \mathrm{~m}$ wide and intersect in an orthogonal system to form polygons that typically measure 5-30 $\mathrm{m}$ in width. In some cases, the cracks form polygons with bimodal size distributions and may be subdivided further below the camera's spatial resolution. They tend to occur in relatively bright deposits that may appear (a) on exhumed outcrops or ridges, (b) within natural depressions, or (c-f) as plain materials. The cracks show a continuum in terms of preservation or "freshness" that ranges from (c) well preserved to (d) degraded. Occasionally, the cracks are (d) filled with dusty material or (b) covered by dunes, and in several cases the entire patterns may be (e) obscured by dusty mantles. There are no discernible patterns in the crack pattern morphologies, size, or preservation state in regard to geographical location or geologic setting. Image IDs are as follows: (a) ESP_016057_1515, (b) ESP_018831_1545, (c) PSP_003160_1410, (d) ESP_016354_1745, (e) ESP_028197_1580, and (f) PSP_008917_17770. 
properties of the chloride-bearing materials as well as those of potential analog mixtures of chlorides (as halite), sulfides (as pyrite), and basalt. They found that the chloride-bearing material displays featureless red slopes in the NIR ratio spectra, which they attributed to a mixture of anhydrous chlorides $(\leq \sim 25 \mathrm{wt} \%)$ and silicate minerals.

[7] Finally, in terms of the spatial or stratigraphical association of the chloride-bearing materials with other mineralogies, Murchie et al. [2009] and Glotch et al. [2010] studied the Terra Sirenum region and reported that it contained multiple exposures of Fe-/Mg-rich phyllosilicates (using CRISM) in association with chloride-bearing materials. Their studies suggested that the phyllosilicates are part of the ancient highland crust and that the chlorides were deposited at a later time with some of the chlorides showing evidence for mobilization and deposition by near-surface waters. Ruesch et al. [2012] carried out a more global spectroscopic analysis of the chloride terrains ( $\sim 400$ locations) using the "Observatoire pour la Minéralogie, l'Eau, les Glaces et l'Activité" (OMEGA) imaging spectrometer [Bibring et al., 2004] and arrived at similar conclusions regarding the phyllosilicates-chlorides association in Terra Sirenum while noting a lack of a similar connection to hydrated minerals on global scale. Their study also indicated a lack of correlation between the chlorides and olivine exposures (thereby further ruling out sulfides as an alternative component to chlorides) [Osterloo et al., 2008] and suggested that groundwater upwelling was the most frequent source of water involved in the formation of the chloridebearing deposits.

\section{Data Sets and Methods}

\subsection{HiRISE}

[8] HiRISE, which is onboard the Mars Reconnaissance Orbiter (MRO) can acquire images at an unprecedented spatial resolution of $0.25-0.5 \mathrm{~m} / \mathrm{pixel}$ [McEwen et al., 2007]. This resolution permits the characterization of meter-scale features on the surface of Mars. As such, we used, almost exclusively, the HiRISE data set to search for and to characterize surface cracks within the chloridebearing materials. Up to the time of this study (completed in April 2013), HiRISE covered 86 locations in Osterloo et al.'s [2010] database of chloride-bearing terrains ( $\sim 13 \%$ of the global data set).

[9] Overall, the image coverage is fairly uniform throughout the data set except for a noticeably lower number of images in the region from $60^{\circ} \mathrm{E}$ to $180^{\circ} \mathrm{E}$ that extends from the eastern circum Hellas region to the western bounds of Terra Sirenum (Figure 1). Only the images that directly cover the chloride-bearing terrains were used to confirm the presence or absence of cracking patterns in a given location. However, we also inspected the HiRISE images that were in close proximity ( $<10 \mathrm{~km}$ away) to one of the locations in the database if that region was of a similar geological setting. If cracks were seen within these images, these locations were marked as "putative" (Figure 1; supporting information). Finally, the retrieval and analysis of the images were carried out in a geographic information system (GIS) environment, JMARS (http://jmars.asu.edu) [Gorelick et al., 2003], which is a free planetary GIS software that includes up-to-date data sets for various instruments from Martian missions and several independent data sets such as Osterloo et al.'s [2010] database, as well as numerous data analysis tools.

\subsection{CRISM}

[10] CRISM onboard MRO investigates surface mineralogy by acquiring hyperspectral data of the Martian surface in the visible NIR spectral range $(0.36-3.92 \mu \mathrm{m})$ at variable spatial and spectral resolutions depending on the selected observation mode [Murchie et al., 2007]. In this study, we only use targeted observations in which 544 spectral images are acquired over the entire spectral range, which provides an average spectral sampling of $6.5 \mathrm{~nm}$. The spatial resolution is about $18 \mathrm{~m} / \mathrm{pixel}$, and the imaged region is typically about $10 \mathrm{~km}$ wide and 10 or $20 \mathrm{~km}$ long.

[11] We used the summary products to quickly check for notable mineralogical criteria then carried out a detailed analysis. All data were retrieved from the Planetary Data System (http://pds-geosciences.wustl.edu) in calibrated (I/F) form using calibration version 3 (Targeted Reduced Data Record, v.3). Only the central observation in the multiangular sequence was used. The downloaded data were processed using the ENVI-CAT Toolkit version 7.2.1 and released by the CRISM team (available at: http://pds-geosciences.wustl. edu/workshops/CRISM_workshop_Mar12.htm). Processing includes the division of the $\mathrm{I} / \mathrm{F}$ values by the cosine of the incidence angle and the correction for atmospheric gas absorption using the commonly used volcano scan method [Langevin et al., 2005; Morgan et al., 2011]. We defined regions of interest inside the processed hyperspectral cubes over terrains showing different reflectance and texture and exported the average reflectance spectra. In order to highlight the spectral signatures of the studied terrains, spectral ratios were calculated by dividing the reflectance spectra of our region of interest by those of a spectrally neutral region. The spectrally neutral region was defined as close as possible to the region of interest, carefully avoiding the periphery of the CRISM image to minimize the influence of spectral artifacts such as spectral smile.

[12] Based on our observations of the spectral diversity in our set of CRISM observations, we have selected three spectral criteria to map the occurrence of the studied minerals. First, in order to map the chlorides, we use a red slope following the work of Jensen and Glotch [2011]. The red slope is calculated as

$$
\text { Red slope }=\left[R_{2.6 \mu \mathrm{m}}-R_{1.0} \mu \mathrm{m}\right] / R_{2.6} \mu \mathrm{m}
$$

[13] In order to map phyllosilicates, we use the band depths at 1.9 and $2.3 \mu \mathrm{m}$, respectively. The $1.9 \mu \mathrm{m}$ band is the absorption band of molecular water and has been used to map hydrated minerals on Mars [Bibring et al., 2006]. The $2.3 \mu \mathrm{m}$ absorption feature is characteristic of phyllosilicates, specifically $\mathrm{Fe}-\mathrm{Mg}$-rich varieties and has been used with success in previous studies [Poulet et al., 2005]. Band depths (BD) are classically calculated as

$$
\mathrm{BD}=1-R_{\text {band }} / R_{\text {continuum }}
$$

[14] For the $1.9 \mu \mathrm{m}$ band depth, we use the spectel at $1.93 \mu \mathrm{m}$ as the bottom of the band and the spectel at $1 \mu \mathrm{m}$ as 

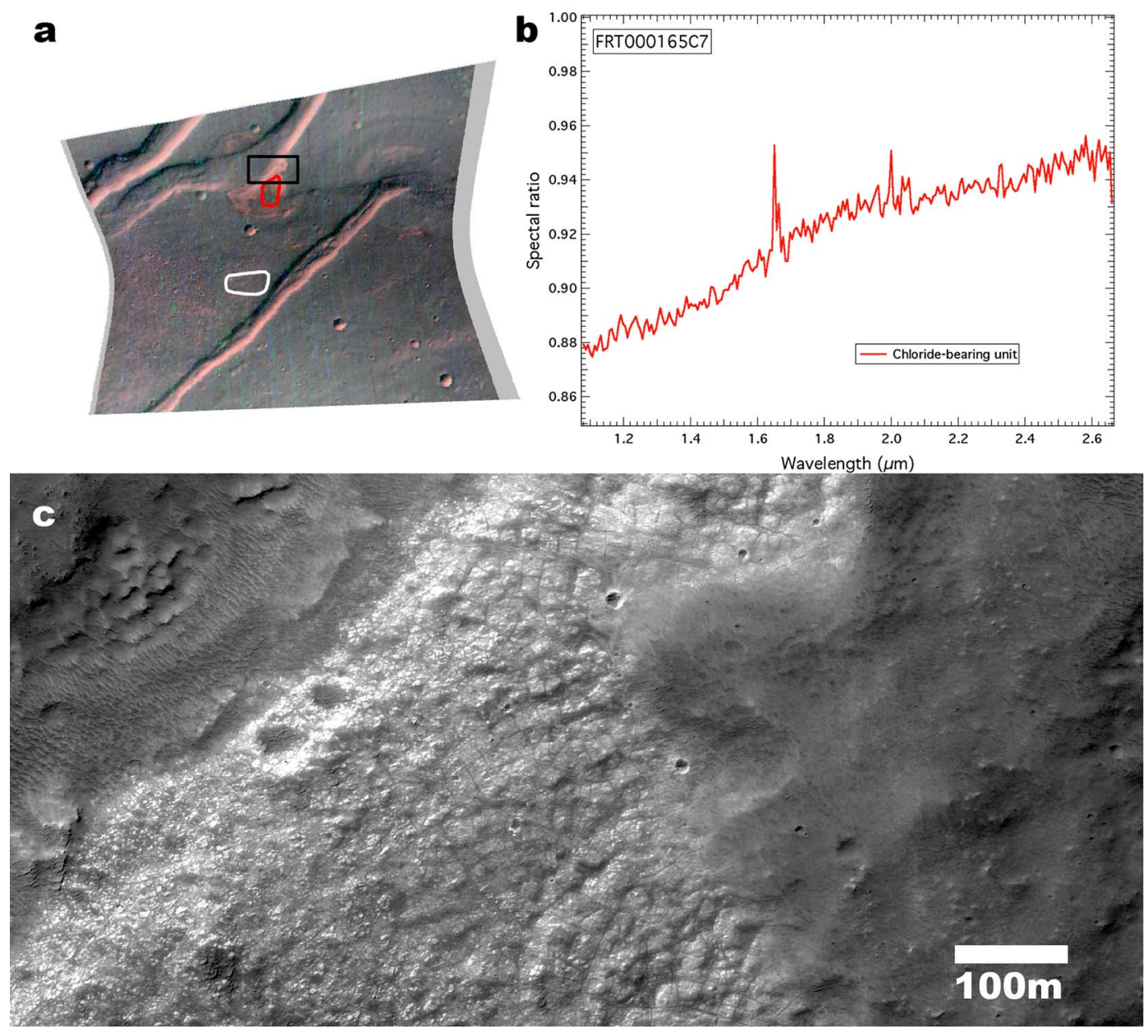

Figure 3. (a) CRISM (ID: FRT000165C7) and (c) HiRISE (ID: ESP_016569_1405) images of chloridebearing deposits in a degraded impact crater that has been modified by extensional tectonic processes. (a) RGB composite of band parameters (see section 3.2) superposed on a map-projected $1 \mu \mathrm{m}$ image which shows the chloride-bearing deposits in red. The black box shows the location of the HiRISE image shown in Figure 3c, while the colored polygons refer to the locations where the spectra have been combined for the chloride-bearing deposits (red) and then displayed as a ratio by dividing it with a spectrally featureless area (white). (b) The chloride deposits display a distinctive featureless near-infrared slope (see section 4.2). The spectral signature of chlorides is limited to the degraded crater and should not be confused with the illuminated slopes of the grabens that appear red because of topographic/photometric effects. (c) HiRISE image of the chloride-bearing deposits in a degraded crater that displays cracking patterns. Note the presence of an overlying dark featureless mantle that partly covers the deposits. Location is centered at $39.3^{\circ} \mathrm{S}, 246.2^{\circ} \mathrm{E}$.

the continuum before the band. For the $2.3 \mu \mathrm{m}$ feature, we estimate its depth using spectels at $2.3 \mu \mathrm{m}$ as the bottom of the band and $2 \mu \mathrm{m}$ as the continuum before the band. Each of these parameters is applied over the entire scene to create a map. These maps are then projected using the procedure provided in the ENVI-CAT toolkit and the ancillary geometric information in the Derived Data Record files. Red-Green-Blue (RGB) color composite images are produced from the three parameter maps. Each color channel is stretched between 0 and a maximum defined independently in each image and for each channel. The color composite is finally superposed onto the map-projected CRISM image at $1 \mu \mathrm{m}$ to assess the spatial correlation between the geomorphological features and the spectral parameters.

\section{Results}

\subsection{Morphology and Geological Setting}

[15] Our investigation of the regions in Osterloo et al.'s [2010] database that are covered by high-resolution images yielded 68 locations that contain cracking patterns close to or directly associated with the chloride-bearing materials. Although this value represents only $\sim 10 \%$ of the global database, it in fact represents more than $75 \%$ of the locations that are mapped by HiRISE (Figure 1; supporting information). Furthermore, additional 27 locations show cracking patterns in close proximity to the chloride-bearing materials but lack direct data coverage to confirm it (see section 3.1). These results suggest that the cracking patterns are a common 
a

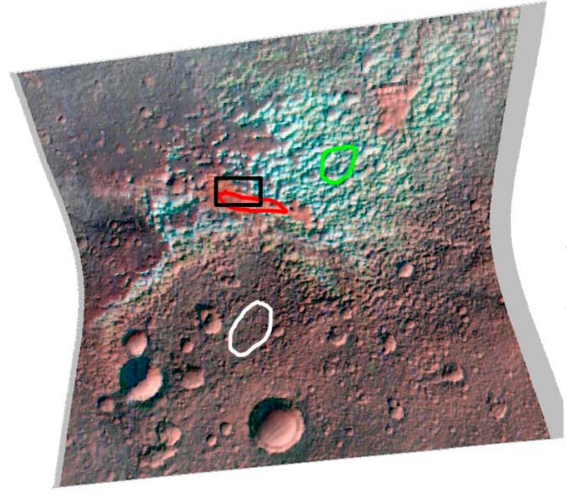

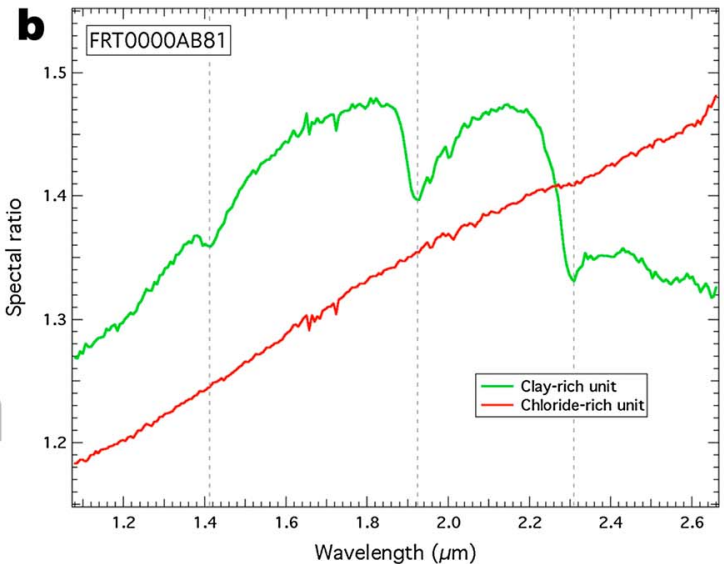

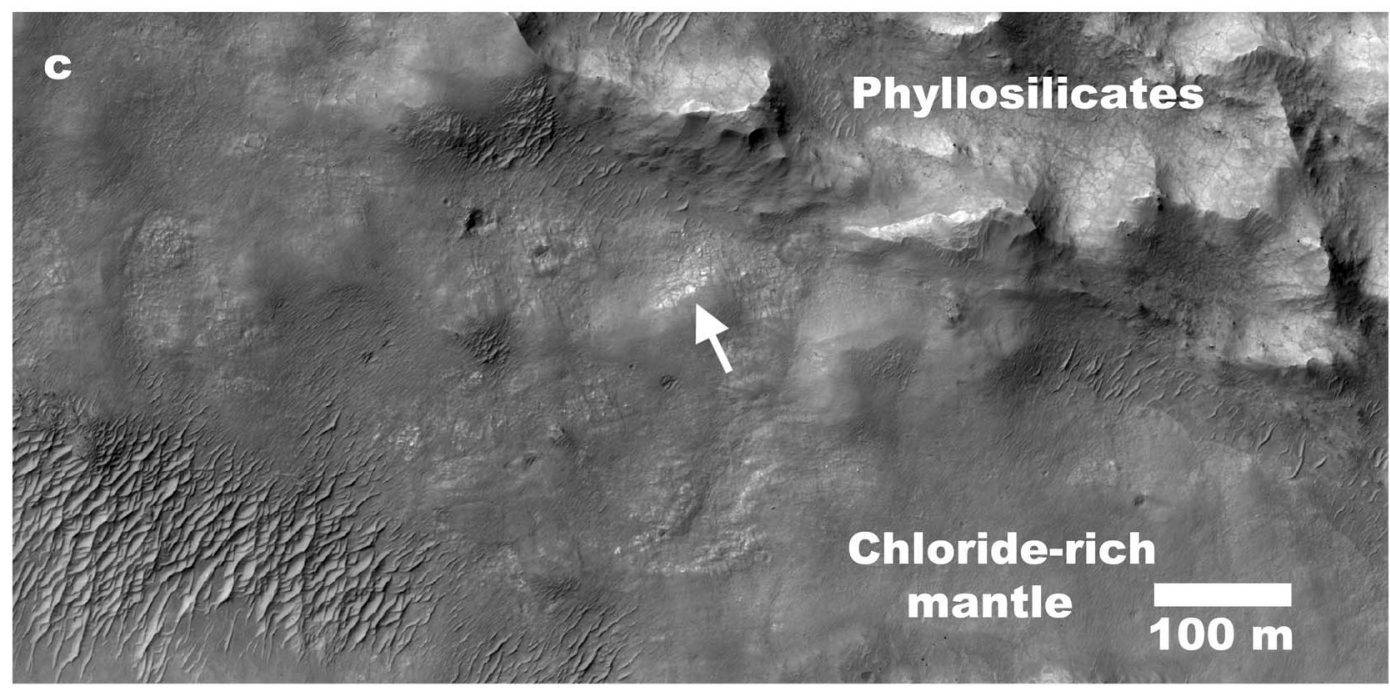

Figure 4. (a) CRISM (ID: FRT0000AB81) and (c) HiRISE images (ID: ESP 016043_1480) of phyllosilicate-bearing terrain covered in parts by chloride-bearing mantles. (a) RGB composite similar to Figure 3 which shows the chloride-bearing deposits in red and clay minerals in green. Black box and colored polygons have similar attributes to previous figures. (b) The average relative spectrum of the phyllosilicate-bearing unit (green) shows deep absorptions indicating Fe-/Mg-rich smectites. Contrary to the general case, the chloride-bearing unit is darker than the phyllosilicate-bearing one at short near-infrared wavelengths in this particular location. (c) HiRISE image showing the bright and fractured clay deposits along with a non-fractured chloride-bearing material. Note the presence of exhumed bright and fractured exposures of phyllosilicates (arrow) beneath the chloride-bearing mantle, which is situated in local topographic lows between the phyllosilicate-bearing deposits (see Figure 10 for an anaglyph). Location is centered at $31.6^{\circ} \mathrm{S}, 206.4^{\circ} \mathrm{E}$.

feature within the chloride-bearing terrains and may represent an important clue regarding their formation. Out of the entire data set that has HiRISE coverage (86 locations), only 16 locations lack visible cracking patterns.

[16] The cracking patterns show a common morphology (Figure 2). All patterns are characterized by polygonal shapes caused by the intersection of fractures in an orthogonal or quasi-orthogonal manner, which is a common trait among tensional cracks such as periglacial, desiccation, and volcanic cracks [e.g., El Maarry et al., 2010, and references therein]. The polygonal patterns are generally flat and lack raised rims or centers. The fractures themselves are usually $1-2 \mathrm{~m}$ wide. The spacing between the fractures (or polygon width) is highly variable across the global data set and occasionally, within the same location. Nevertheless, we have made size estimates for the cracking patterns in the regions mapped by HiRISE at $0.25 \mathrm{~m} /$ pixel (38 locations). The average size estimates were carried out by first locating an area with a uniform polygon size. Next, we counted 20-25 polygons, acquired their surface area, and averaged them to get the area of a single-averaged polygon. Finally, the width was derived with the simplifying assumption that the polygon can be represented by a square of the same area. Overall, primary polygons have a size range of 5-30 $\mathrm{m}$. Acquiring an accurate or precise size estimate proved to be problematic in several locations because many size scales can be present in one location in addition to the presence of secondary and, in a few cases, tertiary generations of cracks nested within the 


\section{a}

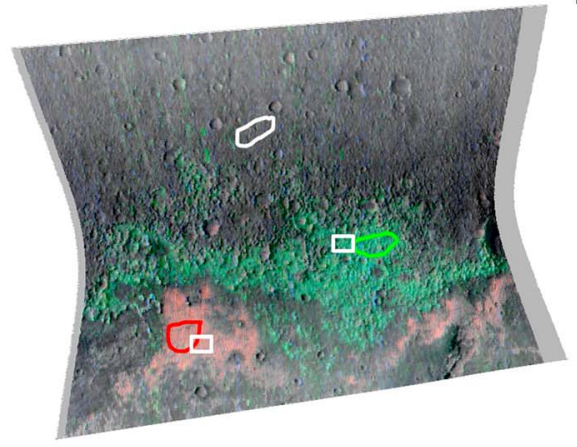

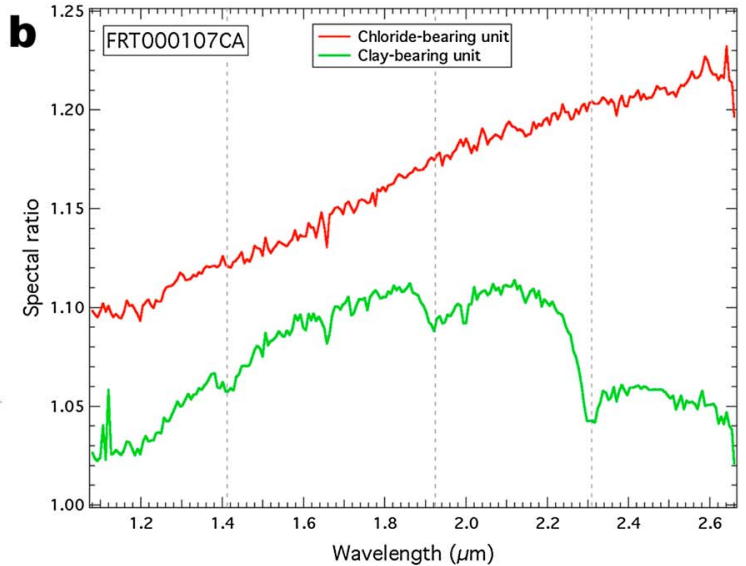
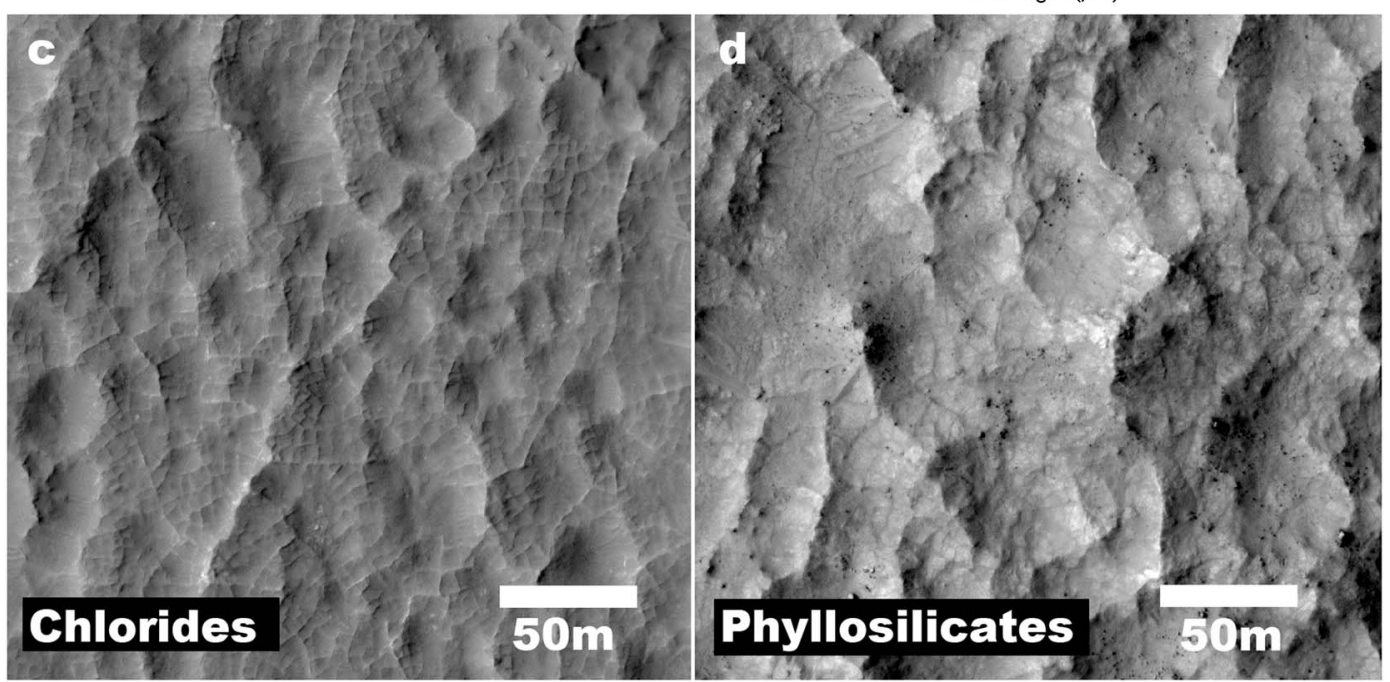

Figure 5. (a) CRISM (, ID: FRT000107CA) and (c, d) HiRISE images (ID: ESP_011547_1475) of phollosilicate- and chloride-bearing, fractured terrains. (a) RGB composite similar to previous figures which shows the chloride-bearing deposits in red and clay minerals in green. White boxes and colored polygons have similar attributes to previous figures. (b) The near-infrared red slope and the depth of the $2.3 \mu \mathrm{m}$ absorption band clearly separate two mineralogical units (chlorides and Fe-/Mg-rich smectites) in close proximity but without spatial overlap. HiRISE images showing polygonal fracture patterns within (c) the chloride- and (d) the phyllosilicate-bearing deposits. Note the raised rims or ridged morphology in the polygonal patterns of the chlorides and the similarity of the patterns in the phyllosilicate-bearing deposits to those of the previous class (Figure 4). Topographically, the chloridebearing terrains are situated in a lower elevation compared to the phyllosilicates. Location is centered at $32.1^{\circ} \mathrm{S}, 191^{\circ} \mathrm{E}$.

primary polygons that are at the resolution limit of the HiRISE image (see for example Figures 2c, 2d, and 2e). As such, we expect that many of the chloride terrains have polygonal cracks down to, and below, the submeter scale.

[17] Regarding the regional setting, the cracking patterns in the chloride-bearing terrains typically form within bright patches and occur as exhumed outcrops in plains or low depressions such as impact craters. Additionally, they also occur within sinuous valleys. The cracking patterns can at times be seen dissecting or overlying dune-like materials, which suggest an underlying indurated mantle. These settings are consistent with Osterloo et al.'s [2010] investigation of the chloride-bearing materials in general. The patterns show variable states of preservation that range from pristine, or fresh looking, to almost completely degraded, which could partly explain the absence of patterns in some of the HiRISE images covering the terrains. The variable preservation state does not necessarily indicate differences in response to weathering conditions (i.e., variable composition) or various formation ages. Instead, it could also indicate a different exhumation age or a variable composition and weathering extent in the overlying deposits since many of the bright deposits appear to have been exhumed following their formation and subsequent burial [see also Osterloo et al., 2010].

[18] Finally, there are no visible trends regarding polygon size or degradation state with geographical location, geological setting, or elevation. Among the non-cracked terrains, a geographical trend is apparent because of a localized concentration within Noachis Terra (Figure 1). However, no further significant trends can be seen in relation to the geologic setting, elevation, or image resolution. 

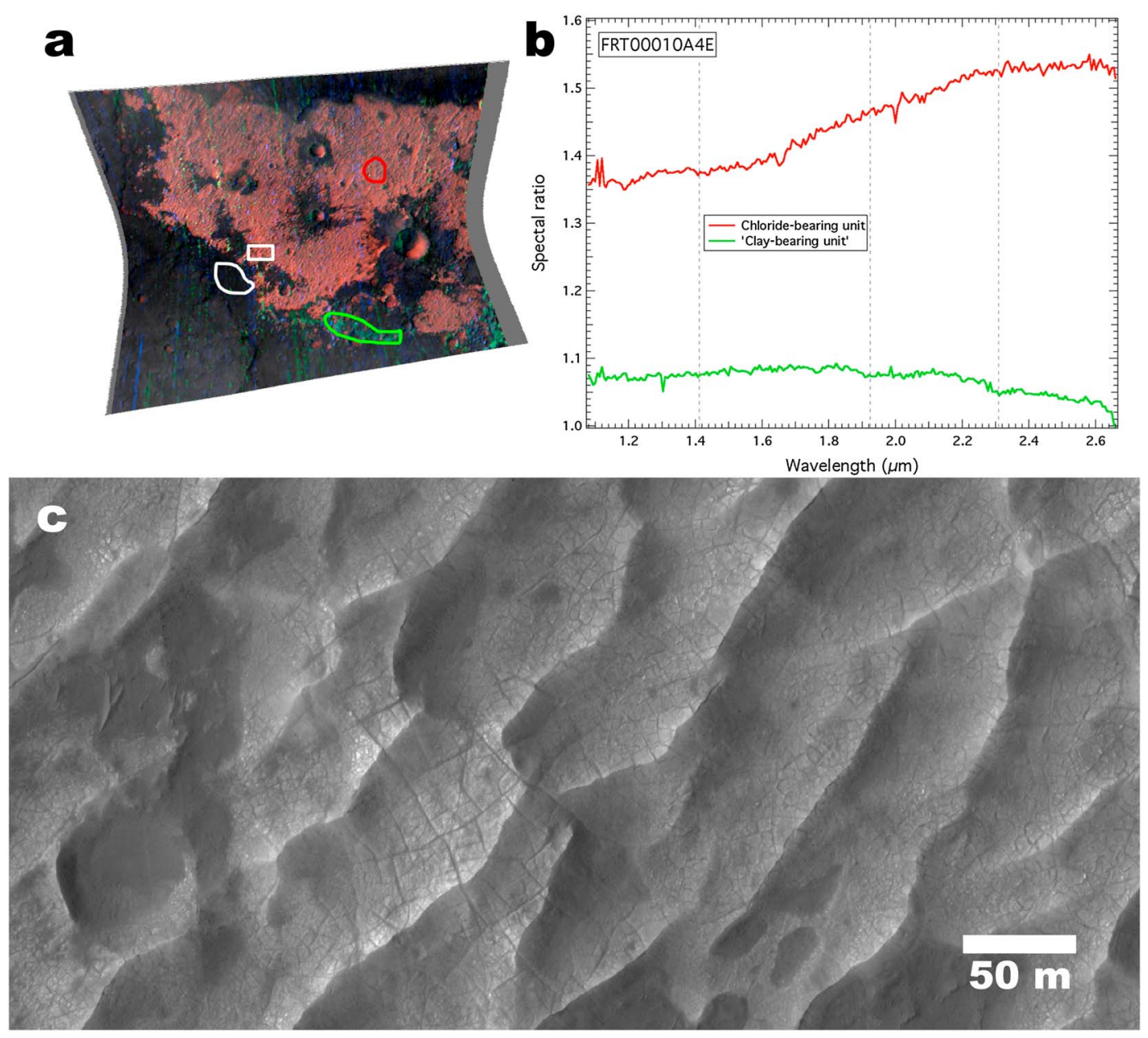

Figure 6. (a) CRISM (ID: FRT00010A4E) and (c) HiRISE images (ID: PSP_003160_1410) of chloridebearing terrain showing an additional weak phyllosilicate signature in its margin. (a) RGB composite similar to previous figures which shows the chloride-bearing deposits in red and clay minerals in green. White boxes and colored polygons have similar attributes to previous figures. (b) The chloride-bearing terrain displays the distinctive red slope, while its margins display a weak signature of clay minerals in green slope. Absorption bands are too faint to allow clear identification of the exact type of mineral responsible for the signature, but the presence of 1.9 and $2.3 \mu \mathrm{m}$ bands is consistent with the Fe-/Mg-rich smectites observed in other locations in this work. No spectral evidence for phyllosilicates could be observed in the craters and dark ejecta that partly cover (a) the bright chloride-bearing unit. As in Figure 3, topographic/photometric effects result in false identifications of the chloride spectral signature on the illuminated slopes of the large craters. The floors of the smaller craters in the southeastern part of the image, however, show the spectral signature of chlorides. (c) HiRISE image of the well-preserved cracking patterns within the chlorides. Notice the ripple-like morphology of the deposits, which may indicate an indurated nature for the deposits. The dark featureless mantles are mostly ejecta from consequent impact events and suggest that the chloride-bearing deposits are thin in extent because they are not apparent within the crater floors, walls, or their ejecta. Location is centered at $38.8^{\circ} \mathrm{S}, 221.1^{\circ} \mathrm{E}$.

\subsection{Mineralogy and Stratigraphical Setting}

[19] To characterize the mineralogical diversity associated with the chloride-bearing materials, we investigated further the locations displaying cracking patterns that have CRISM cover. Out of the 68 locations, 43 locations with various geological settings are covered by CRISM ( $60 \%)$. Our investigation reveals that almost one third (14 locations) of the fractured regions covered by CRISM have clear signatures of Fe-/Mg-rich phyllosilicates. Based on our analysis of several of these locations in detail regarding their stratigraphical relations and spectral signatures, we have grouped these locations into three main classes in terms of the chloride-phyllosilicate association and the composition of the fractured unit. Excluded from these classes are 11 locations that are generally spectrally featureless possibly due to an extensive dust cover.

\subsubsection{Fractured Chlorides Without a Phyllosilicate Signature (17 Locations)}

[20] This class represents the majority of the studied locations. In this class, no NIR spectral signatures of hydrous 
minerals are observed (Figure 3 ). The cracking patterns are directly associated with the bright chloride-bearing regions that show a distinctive near-infrared positive red slope. Most of the units in this class appear to be represented by exhumed bright deposits in plains that are partly overlain by dark and spectrally featureless material (e.g., Figure 3). In some notable cases, the deposits form sinuous ridges or are located in impact craters that show signs of degradation or even modification by tectonic processes (Figure 3 ).

4.2.2. Non-Fractured Chloride-Bearing Mantles/Crusts Overlying, or in Proximity to, Fractured Phyllosilicates (11 Locations)

[21] This class is dominated by fractured phyllosilicates that are usually partly covered by mantles of chloride-bearing materials (Figure 4) and is mainly concentrated in the Terra Sirenum region. The spectra display strong absorption bands at $1.4,1.9$, and $2.3 \mu \mathrm{m}$, which are characteristics of $\mathrm{Mg}-/ \mathrm{Fe}-$ rich smectites, and the chloride-bearing mantles are directly associated with the regions identified by Osterloo et al. [2010] and show the distinctive featureless red slope. Occasionally, phyllosilicate exposures are exhumed from beneath the chloride-bearing mantles (see Figures $4 \mathrm{c}$ and 10). It is difficult to infer whether the chlorides are thin mantles that were deposited at the time of the phyllosilicates formation or if they are indurated aeolian deposits that have covered the phyllosilicates at a later time. It is possible that both processes have occurred, in different locations, but are difficult to differentiate from one another.

\subsubsection{Fractured Phyllosilicates and Fractured} Chlorides in Close Proximity (4 Locations)

[22] A minority of locations shows phyllosilicates and chlorides in close proximity to one another and both are fractured (Figures 5 and 6). This class can be further subdivided into two subclasses (2 locations each). In the first case, the strong phyllosilicate signatures and cracking patterns are similar to those of the previous class (section 4.2.2; Figure 5d). However, the chloride-bearing materials show polygonal patterns that are not morphologically similar to those of phyllosilicates or even those of the chloridebearing terrains that do not display a phyllosilicate signature (see section 4.2.1). The patterns are usually composed of polygonal narrow ridges (Figure 5c), which may indicate either extensive erosion leading to inverted-like topography or repeated filling of the fractures leading to the development of raised rims.

[23] In the second case, the fractured patterns in the phyllosilicates and chlorides resemble each other (Figure 6). The phyllosilicate signatures can be significantly weaker than in other classes but are, nonetheless, represented by the 1.4- 1.9, and $2.3 \mu \mathrm{m}$ absorption bands indicative of $\mathrm{Mg}$-/Fe-rich smectites (Figure 4), which is the main class of phyllosilicate minerals observed in this study.

\section{Discussion}

[24] In the following sections we assess the desiccation hypothesis (see also Appendix A) for the formation of polygonal cracks as well as alternative mechanisms. Next, we discuss the different chlorides-phyllosilicates stratigraphical relations observed in this study followed by potential terrestrial analogs. Finally, we discuss the implications of using the cracking patterns as paleoenvironmental and lithological indicators (e.g., as a way to decipher composition and thickness of the units containing them).

\subsection{Desiccation Hypothesis and Alternative Mechanisms}

[25] Cracking patterns may develop in many geological settings and can have different formation mechanisms. However, the size scale of the patterns seen in this study (2-30 m wide polygons) is commonly formed by buildup of tensile stresses through either thermal contraction in a periglacial setting or desiccation in transient hydrologically active conditions in arid, typically warm, climatic settings [El Maarry et al., 2010] (Appendix A). Thermal cooling of volcanic deposits may also lead to the development of cracking patterns, which are known commonly on Earth as columnar joints. However, these structures tend to form (quasi)-hexagonal patterns in plain view at smaller size scales than those observed in this study [Ayden and DeGraff, 1988; Grossenbacher and McDuffie, 1995]. Similarly, the geological setting and geography of the chloride-bearing terrains (local topographic lows in equatorial and midlatitudes), surface properties (high albedo and smooth textures), and spectral information from this study and others does not collectively support a volcanic or periglacial setting. In addition, numerical simulations of thermal contraction polygon development and size range [e.g., Mellon, 1997] suggest that the development of periglacial polygonal cracks in the current climate in equatorial and midlatitudes is highly unlikely because of the lower seasonal temperature variations compared to the higher latitudes. Furthermore, it is unlikely that the process of thermal contraction in a periglacial setting would form polygons $<5 \mathrm{~m}$ wide because it would require significantly higher thermal stresses than can be achieved in the current climate given the range of surface thermal inertias on Mars and current seasonal temperature fluctuations [Mellon et al., 2008]. As a result, we favor the desiccation hypothesis, which was originally suggested by Osterloo et al. [2008, 2010], for the chloride-bearing terrains as well as the phyllosilicate-bearing units. This hypothesis has important implications for the ancient climate on Mars as well as its hydrological activity.

\subsection{Chloride-Phyllosilicate Stratigraphies}

[26] Among the chloride-bearing terrains, the most common setting observed in this study is that of regions that display no phyllosilicate signatures within the fractured chlorides (section 4.2.1). However, the fracturing patterns observed in the chlorides (with the exception of two locations) resemble those of phyllosilicate-rich deposits in the other two classes that show strong phyllosilicate signatures (compare Figures 3-6). Furthermore, in the cases where fractured chlorides and fractured phyllosilicates are seen in close proximity (section 4.2.3), two particular locations (second subclass) contain phyllosilicates and chlorides that are in close proximity to each other and are displaying similar fracturing patterns in terms of overall morphology, albedo variations, and size. One of these locations is shown in Figures 7 and 8. By comparing the geological setting (Figure 7) and the morphology of the cracking patterns in two spectrally distinct units (Figure 8), we can infer that both locations are in fact part of the same geological unit 


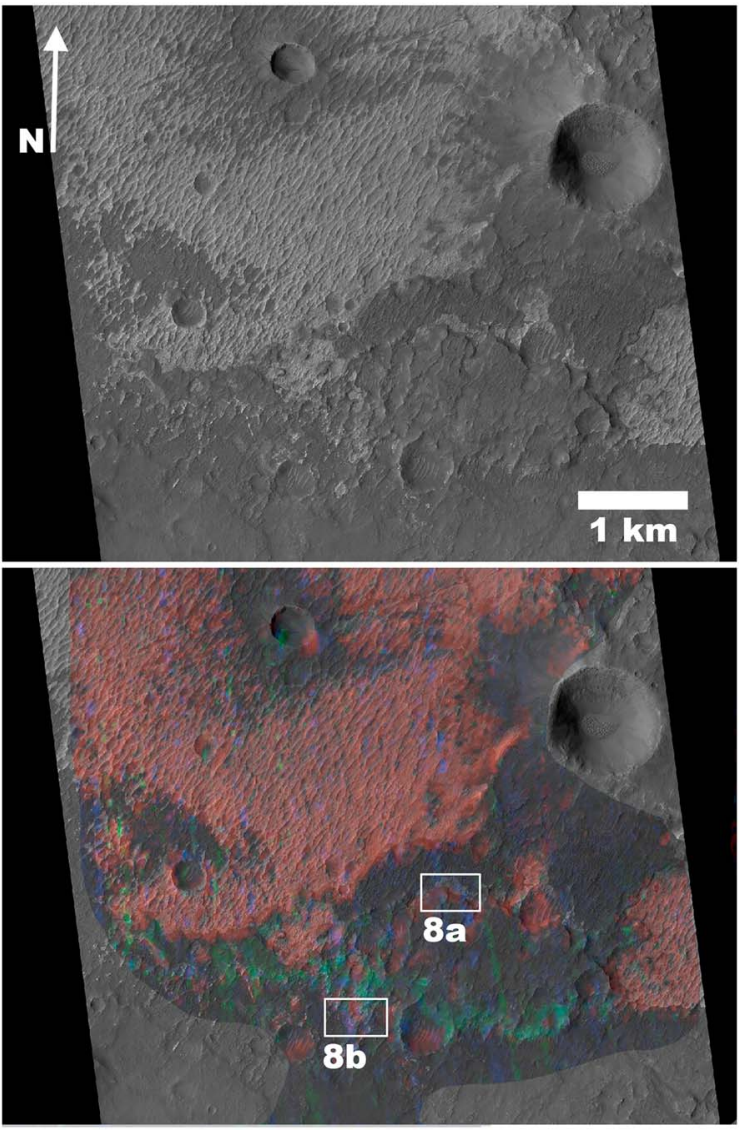

Figure 7. (top) HiRISE (PSP_003160_1410) image of fractured chloride-bearing terrains and (bottom) a similar image with an overlay of CRISM (FRT00010A4E) band parameters where red corresponds to chloride-bearing terrains, while green corresponds to phyllosilicate-bearing deposits at immediate vicinity. Note the similarities in terms of brightness between both deposits and the apparent lack of high elevation differences which, in the absence of spectral variations, could simply represent two exhumed sections or outcrops of the same deposit. White boxes show the locations in Figure 8.

comprising bright exhumed deposits despite the different spectral signatures.

[27] In the third class, the chlorides are associated with a mantling unit covering the phyllosilicates (Figure 9). The thickness of this mantling unit is unclear, but it could be thick enough to obscure possible phyllosilicate signatures from the underlying unit(s) as is seen in Figure 9 where certain patches of fractured phyllosilicates appear to be exhumed within the chloride-bearing mantle. Within these locations, the chlorides may either be a friable unit that has been eroded away to reveal the phyllosilicates or an aeolian deposit, indurated and potentially being eroded away in the same manner. In light of the available data, it is not possible to differentiate between the two processes, but it is expected that both have been responsible for the formation of this type of stratigraphical relationship.

[28] In section 4.2, chloride-bearing terrains displaying cracking patterns were divided into three classes in terms of phyllosilicates-salt association and the presence of fracturing. However, we can rearrange these classes in terms of phyllosilicate spectral abundance to form a continuum ranging from (a) regions containing fractured chlorides (with phyllosilicate-like morphologies) that are devoid of, or show weak, phyllosilicate signatures (Figures 3 and 5), (b) weak to strong phyllosilicate signatures along with fractured chlorides (Figures 5 and 6), and finally, (c) regions with strong phyllosilicate signatures and non-fractured chloride-bearing mantles (Figure 4). Given these associations and our current understanding of the requirements for the formation of desiccation cracks in the size scales observed in this study (section 4.1 and Appendix A), we conclude that the presence of smectite-rich soils in all the chloride-bearing terrains is the most plausible explanation for the development of surface cracking patterns in spite of the lack of spectroscopic confirmation.

[29] This hypothesis appears contradictory to previous conclusions by other studies [Glotch et al., 2010; Ruesch et al., 2012, section 2]. For instance, Ruesch et al. [2012] analyzed the mineralogical compositions in the chloridebearing terrains using data from the OMEGA imaging spectrometer. One of their conclusions was the lack of association of chlorides with hydrated minerals globally (e.g., phyllosilicates, sulfates, and hydrated silica). However, we propose a number of factors that can address the apparent discrepancies. A notable difference between our study and that of Ruesch et al. [2012] lies in the different methods and data sets that were used. In our study, we have used the CRISM data, which is more limited in ground coverage yet offers a better spatial resolution than OMEGA. Ruesch et al. reported that only $9 \%$ of their surveyed sites $(\sim 40$ out of $\sim 500)$ indicate the presence of hydrated minerals within a $60 \times 60 \mathrm{~km}^{2}$ sized window. In our study, we found that $\sim 30 \%$ of our surveyed sites (14 out of 43 ) have clear Fe-/Mg-rich phyllosilicate signatures within the typically $10 \times 10 \mathrm{~km}^{2}$ sized CRISM images. However, our analysis shows that most of the spectral signatures of phyllosilicate-bearing deposits are situated in Terra Sirenum (Figure 1b), which is in agreement with both the studies of Ruesch et al. [2012] and Glotch et al. [2010]. Nonetheless, our study has the advantage of having a greater number of higher spatial resolution images over the chloride-bearing terrains because of the continually expanding HiRISE database and our use of CRISM, which allowed us to carry out a more detailed inspection of the co-occurrence of phyllosilicates. For example, Ruesch et al. propose that the limited areas with phyllosilicateschloride associations in their data set suggest two separate episodes of mineralization. However, their conclusions (and those of Glotch et al. [2010] for Terra Sirenum) are based on their observations of phyllosilicate-chloride associations mostly similar to the co-occurrences observed in Figures 4 and 10 (in fact, the exact region is discussed by Ruesch et al. in Figure 13). Taking only such locations into account, it would be natural to arrive at the same conclusions of Ruesch et al. [2012]. Indeed, the class of chloride exposures with no phyllosilicate signatures is also the most common spectral class observed in our study. However, the NIR is limited to the upper tens of microns of the surface and our analysis using higher resolution visible data has allowed us to observe different phyllosilicatechloride stratigraphies (section 4.2). We observe a high 

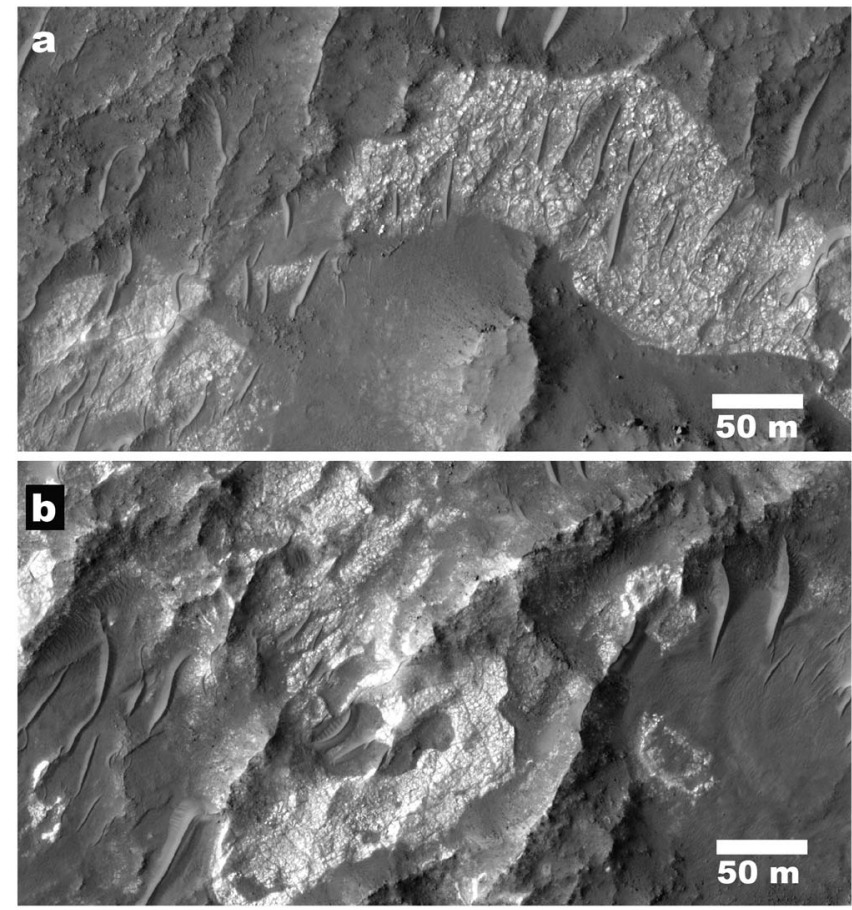

Figure 8. HiRISE (PSP_003160_1410) view of the cracking patterns within the (a) chloride-bearing and (b) phyllosilicate-bearing regions. Note the similarities in cracking patterns in terms of setting, morphology, albedo variations, and size. These images imply that the same geological unit is displaying different spectral signatures. Locations of the images are shown in Figure 7.

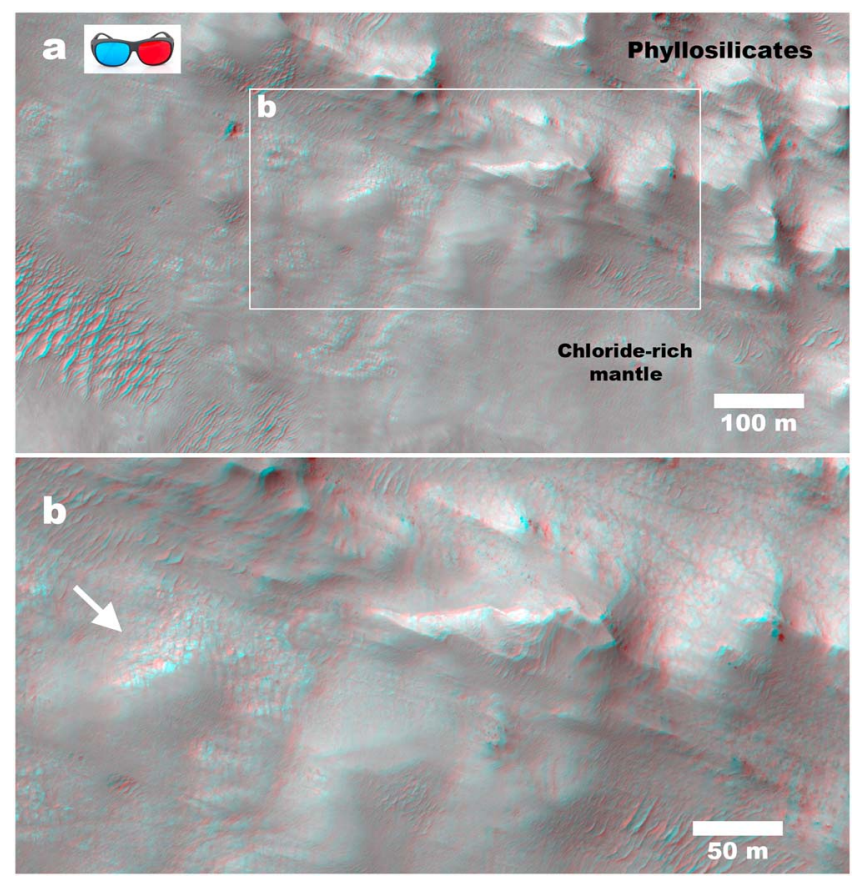

Figure 9. HiRISE anaglyph (ESP_016043_1480 and ESP_016188_1480) for a chloride-bearing terrain with strong phyllosilicate spectral signatures (see Figure 4). The chloride-bearing deposits appear in the form of a dark mantle that covers in some parts the bright fractured phyllosilicate-bearing knobby deposits. The white box in Figure 9a image shows the location of the close-up in Figure 9b. Some parts of the mantle are overlying fractured phyllosilicates (arrow). 


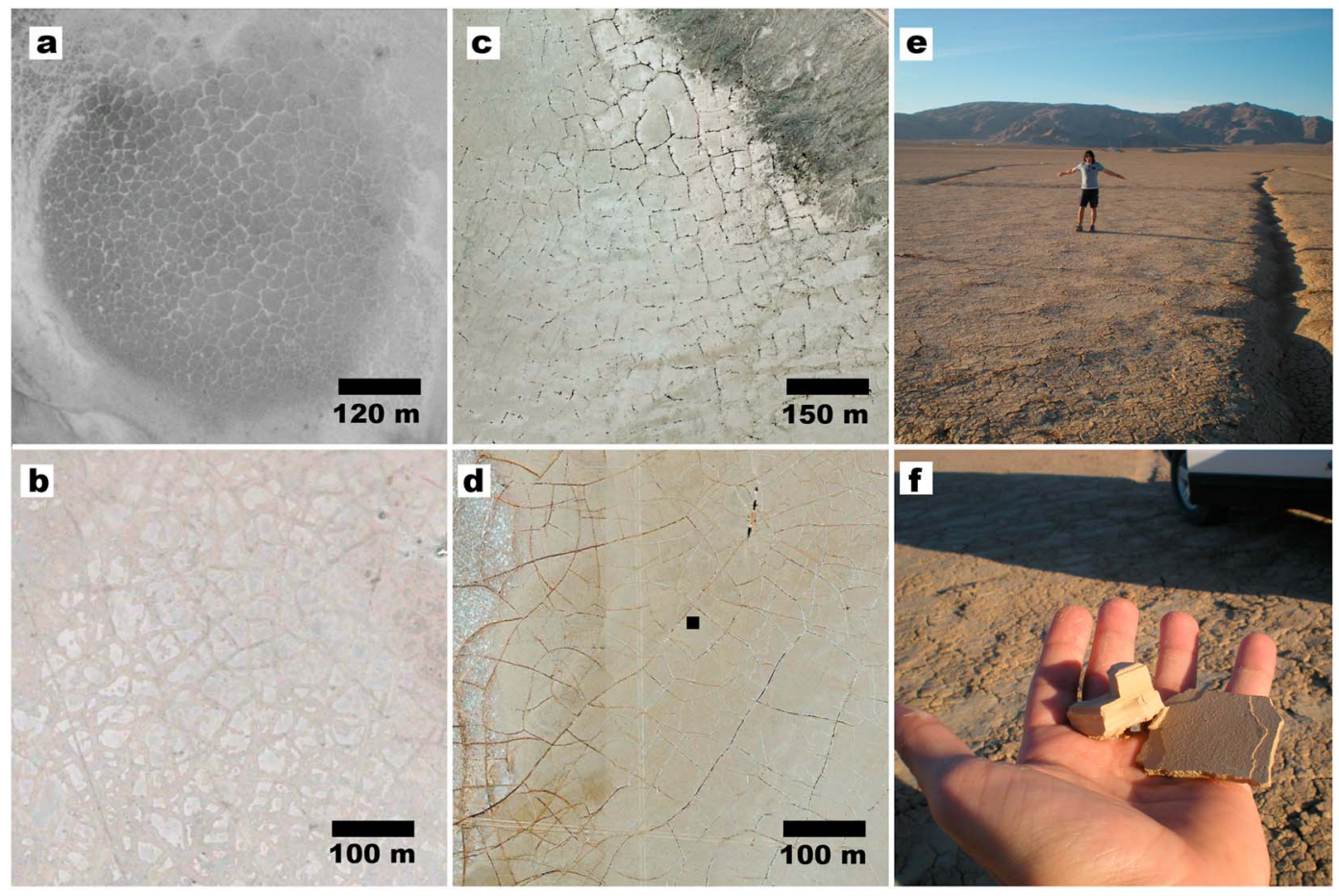

Figure 10. Playas on Earth (all located in California, USA) that display tens of meters wide desiccation polygons. (a) Deep Springs Valley playa $\left(37.25^{\circ} \mathrm{N}, 118.03^{\circ} \mathrm{W}\right)$, which is a salt-rich playa [Neal et al., 1968 ; Lawrence et al., 1978] that usually hosts an ephemeral lake during the wet season (image shown here was taken in 1998). This location is a potential analog to some of the chloride-bearing terrains on Mars. (b) Lavik playa $\left(34.6^{\circ} \mathrm{N}, 116.3^{\circ} \mathrm{W}\right)$. (c) Coyote playa $\left(35.1^{\circ} \mathrm{N}, 116.7^{\circ} \mathrm{W}\right)$. (d) Lucerne playa $\left(34.5^{\circ} \mathrm{N}\right.$, $116.9^{\circ} \mathrm{W}$ ). Black dot shows the approximate location of Figures 10e and 10f. (e) Image of large desiccation cracks in Lucerne playa that were taken by the first author (shown for scale) during a field trip in January 2012. (f) A sample of the playa surface material. Note the platy and sheet-like morphology which is strongly indicative of clay minerals that are a main mineralogical constituent of playa deposits and a main contributor to the development of large desiccation cracks on playa surfaces. Image credits for Figures 10a-10d are Google Earth and the US geological Survey.

correlation between the presence of small- to intermediatesized cracking patterns (2-30 m wide) and the chloride materials which, based on similarities to terrestrial cracking patterns and our models, is suggestive of the presence of phyllosilicate-enriched soils

[30] Jensen and Glotch [2011] have demonstrated experimentally that high concentrations of chloride salts $(\sim 25 \mathrm{wt}$ $\%$ ) may be needed to produce the positive red slope signature seen by CRISM. As such, it is possible that the chlorides are forming thick layers/crusts that are capable of obstructing phyllosilicate detections in the NIR data in many of the locations studied here and that of Ruesch et al. [2012]. Therefore, we do not consider the previous studies to be in contradiction to our conclusions. Instead, we consider our study to be supplementary because of the spatial difference in the spectral data sets used, our updated high-resolution visible image database, and our use of a non-spectral marker (the cracking patterns) to indicate the presence of phyllosilicate-rich deposits.

[31] To summarize, we conclude that the presence of smectite-rich soils in all the chloride-bearing regions is the most plausible explanation for the development of surface cracking patterns. This conclusion implies that the cracking patterns can be used as a physical textural evidence for the presence of phyllosilicates (particularly smectites), even in the absence of spectral confirmation. We suggest that mixing with other spectrally featureless components (such as salts) or the presence of various mantling agents (e.g., dust and duricrust) could hide the phyllosilicate signatures. It should be noted that McKeown et al. [2013] have recently carried out a relevant study of the surface textures of phyllosilicatebearing units in Mawrth Vallis and observe a similarly strong correlation between the presence of polygonal cracking patterns and the presence of smectites.

\subsection{Terrestrial Analogs: Playas}

[32] The most appropriate terrestrial analog for most of the observed settings in this study is salt-rich lacustrine playasgenerally with the exception of sites where chlorides might be an aeolian-mobilized unit (section 4.2.2). They have been similarly proposed as analogs in previous studies [Osterloo et al., 2008, 2010; Glotch et al., 2010; Ruesch et al., 2012]. Playas are located in many arid environments on Earth including hot environments, particularly Africa, Australia, and Western USA, as well as cold regions such as 


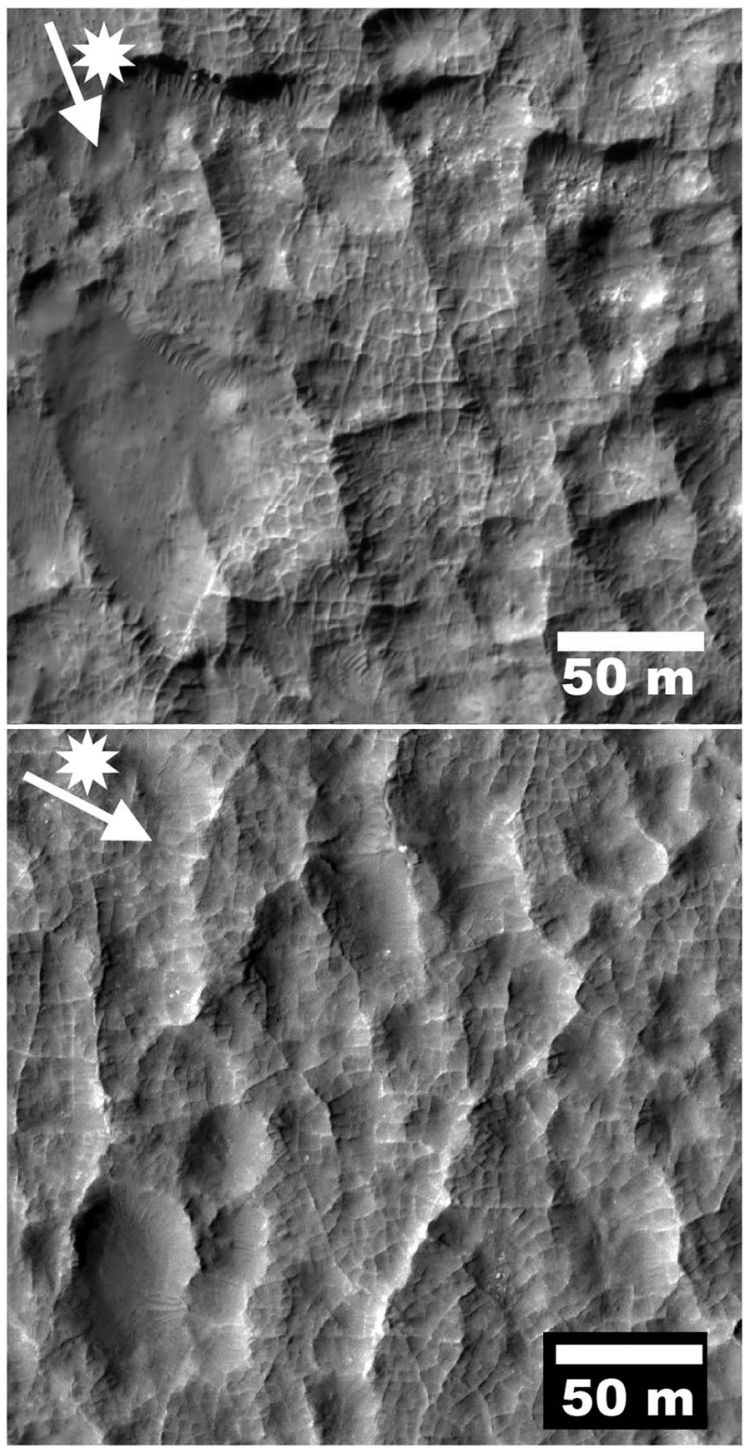

Figure 11. HiRISE images showing peculiar surface patterns within two of the chloride-bearing terrains. The patterns are composed of elevated bright ridges that intersect in quasiorthogonal manner. The morphology, general bright albedo, and geological setting suggest that these features are salt expansion, or salt thrust, polygons (see text). They are found in close proximity to fractured phyllosilicates that show the typical fracturing patterns seen in this study. Image IDs are (top) PSP_009846_1475 and (bottom) ESP_011547_1475.

Antarctica [Shaw and Thomas, 1997; Lyons et al., 1998; Shaw and Bryant, 2011, and references therein].

[33] Playas tend to occupy topographical lows, which become local focus points for the accumulation of water in ephemeral lakes. These lakes can become extremely saline with intense desiccation and occasional recharging. As a result, the evolution of a playa over time is highly dependent on groundwater activity. This activity as well as the elevation of the water table with regards to the playa surface has a major role in the playa's soil composition and the amount of salts it contains. Generally, the closer the water table is to the surface, the more salty the playa becomes as a result of the periodic recharging of the ephemeral lake and consequent accumulation of salts with desiccation. However, if the water table lies at depth, then the salt concentrations become minimal in the playa's clay-rich surface.

[34] Typical minerals in playas include clay minerals, in particular, smectites and illites, as well as carbonates and salts. Out of these minerals, smectites are the main contributor to the formation of desiccation polygonal cracks because of their affinity to accommodate large volumes of water within their chemical structure, which leads to significant volume changes upon desiccation. As a result, large desiccation cracks (several to tens of meters wide polygons) tend to occur in phyllosilicate-rich soils irrespective of the salt content on the surface as shown in several terrestrial analogs (Figure 10). In fact, most of, if not all of, the reported cases of giant desiccation polygons are restricted to playas [Neal et al., 1968].

[35] It should be noted that some fracture patterns in the chloride-bearing terrains are morphologically different from the patterns in the phyllosilicate-bearing units in close proximity (first subclass in section 4.2.3, Figure 11). The patterns are composed of interconnected bright and narrow ridges that do not necessarily obey the orthogonal intersection patterns that are common among typical tensional cracks and most features in this study. The small size of the polygons (typically $<5 \mathrm{~m}$ ), the elevated nature of the rims, and the high albedo resembles features observed in salt expansion or salt thrust polygons, which are common in saline playas on Earth [e.g., Shaw and Bryant, 2011]. Salt polygons form when cycles of consecutive hydration and dehydration lead to preferential deposition of salt crystals along the margins of the polygons that could be accompanied by the extrusion of underlying expanding mud (either due to temperature variations or rehydration). Salt expansion polygons are typically a few meters wide, and their presence would imply cyclic natures of hydration and potentially multiple water table recharging.

\subsection{Implications}

[36] The presence of surface cracking patterns in association with the chloride-bearing terrains has considerable implications for our understanding of the hydrologic activity in the Noachian period. The primary implication for the presence of the cracking patterns is the presence of smectite clays in association with the chlorides; a correlation that has been observed spectrally in several locations in our study. This implies that many of the chloride-bearing terrains have a lacustrine origin that may have been linked to surface water, as well as groundwater, activity. Furthermore, the presence of salts in association suggests that these lakes were not perennial "one-time" lakes but were alternatively ephemeral lakes that were recharged and desiccated numerous times, probably through near-surface groundwater fluctuations. These led to the accumulation of salts within these Martian ancient "playas" and were responsible for the formation of additional surface pattern expressions such as the putative salt expansion polygons that have been observed in our study. More importantly, the presence of desiccation cracks within a playa-like setting suggests that the climate during the Noachian was more accommodating for the presence of liquid water on the surface, at least transiently. 
[37] Finally, it should be noted that the size and morphology of the surface cracking patterns can be used as a stratigraphical tool as well as a paleoenvironmental one. For instance, the more regular the patterns are, the more homogenous the phyllosilicate-bearing units are expected to be. In addition, the size of the polygons is a direct response to the depth of the cracks that form them [El Maarry et al., 2010, and references therein]. In this study, several locations display polygonal patterns that are 20-30 m wide. Given that typical fracture spacing-to-depth ratios for tensile cracks in soils is 10:1-3:1 [see El Maarry et al., 2010, and references therein], we can infer that the minimum thickness of the phyllosilicate-rich units within such chloride-bearing terrains is $2-10 \mathrm{~m}$ thick, which can be of significant aid in the planning of further in situ exploration.

\section{Summary and Conclusions}

[38] We have analyzed high-resolution visible images and spectral data from the HiRISE and CRISM instruments, respectively, to characterize the surface textures associated with the chloride-bearing terrains. Our analysis reveals that most of the regions that were studied display polygonal cracking patterns associated with, or in proximity to, the chloride-bearing materials as well as the occurrences of phyllosilicates near the chlorides. We suggest that desiccation is the mechanism for formation of polygonal cracks, which further implies the presence of smectite-rich layers in association with the chlorides. The spectral analysis indicates that almost a third of the studied chloride-bearing terrains also display signatures of Fe-/Mg-rich smectites. Within the framework of this hypothesis, we suggest that the high salt concentrations, overlying dust covers, or thick indurated mantles/crusts (either chloride bearing or spectrally featureless) may be responsible for obscuring the spectral signatures of the smectite clays in the fractured chloride-bearing terrains. We suggest that salt-rich playas are the most likely analog for these regions, which indicates extensive hydrological activity, although possibly transient and may have involved multiple recharging events by a near-surface fluctuating water table to account for the salt-phyllosilicate associations. Finally, the cracking patterns can be used as a paleoenvironmental as well as a stratigraphical indicator that can be used to investigate the composition and minimum thickness of the layers that contain them. As such, polygonal patterns can be a valuable tool for planning future planetary missions.

\section{Appendix A}

\section{A1. Desiccation Mechanism: Background and Formation of Large Polygonal Features}

\section{A1.1. Background}

[39] In general, soils, or any geological materials, shrink/ swell in response to changes in stress conditions. This can be achieved either through loss of volume in response to cooling or through loss of volatile material such as ice or liquid water, i.e., desiccation. Desiccation is usually achieved through evaporation from the surface or diffusion processes that can manifest either in the migration of liquid water due to differences in water potentials or vapor transport due to changes in water vapor pressure. The degree to which a soil contracts with loss of volatiles depends on its capacity for holding these volatiles on a macroscale through having a significant pore or void volume within the solid structure and on a microscale through its chemical activity and/or ability to accommodate volatile molecules within its crystal structure [El Maarry et al., 2012a]. Generally, the higher the fraction of clay-sized particles (grain size $<2 \mu \mathrm{m}$ ) the soil contains, the more it will shrink with desiccation. In addition, some clay minerals are known for their chemical affinity to swell and accommodate considerable amounts of water through formation of water interlayers on a molecular level. The most pronounced effect of this swelling/shrinkage behavior is found in the smectite clays such as nontronite, saponite, and montmorillonite [Velde, 2010]. These are all common phyllosilicates on the surface of Mars with $\mathrm{Fe}-\mathrm{Mg}$-rich smectites (nontronite and saponite, respectively) being the most common phyllosilicate observed in this study. These phyllosilicates' swelling/shrinking properties are caused by the presence of low charges, which allow hydrated or polar ions (like water) to be inserted between the mineral's layers.

\section{A1.2. Formation of Large Desiccation Polygons on Earth}

[40] There is a notable discrepancy between planetary science and classical geology in regards to the description of sizes of polygonal cracks. On Earth, there are very few well-documented examples of what is termed "giant desiccation polygons" from the geological record [Loope and Haverland, 1988]. Such polygons can be anywhere from tens of meters wide and up to $300 \mathrm{~m}$ in size [Neal et al., 1968]. However, this size range falls within the range-termed intermediate-sized polygons on Mars [e.g., Seibert and Kargel, 2001; Mangold, 2005; El Maarry et al., 2012a] to differentiate it from the Kilometersized "giant" polygons of Utopia Planitia [Pechmann, 1980; Mc Gill and Hills, 1992]. As such, these descriptive terms should be used with caution to avoid misinterpretation.

[41] Detailed field analysis by Neal et al. [1968] at 39 locations in the United States containing "giant" desiccation polygons (up to $300 \mathrm{~m}$ wide) has shown that the sediments are remnant lacustrine clays and silts from former lakes. These sediments can often be more than $50 \mathrm{~m}$ thick and were shown to be composed of predominantly fine soils ( $2 \mu \mathrm{m}$ grain size on average) containing clay minerals such as montmorillonite, illite, and vermiculite in addition to carbonates and analcites [Neal et al., 1968; Harris, 2004]. These large features have been proposed to form through the slow lowering of a water table rather than simple surface evaporation, which would permit the buildup of stress in thick beds within long time periods of 1-2 years [Neal et al., 1968]. El Maarry et al. [2012a] used numerical modeling to show that only clay-rich soils have the sufficiently low diffusivities (i.e., low permeabilities) to allow the buildup of enough tensile stresses to cause fracturing within these slow time scales by assuming a simple case of gravitational lowering of a water table. 
[42] The specific chemical properties of phyllosilicates, especially those of smectites, allow them to shrink considerably with dehydration to create high tensile stresses while the low diffusivities caused mainly by the fine grain size lead to a very slow buildup of stress (and low rates of desiccation if lowering of the water table is involved). This allows thicker mediums to be affected and, in return, the development of deep fractures with large spacing between them [El Maarry et al., 2010]. In contrast, surface evaporation (especially in hot climates) affects only the upper thin layers of a wet material and would lead to smaller fractures with small spacing (centimeters to meters sized) that would form rather quickly (a few hours or days). As a result, the size and spacing of the desiccation cracks can yield profound insight into soils composition and hydrological activity as well as climatic conditions.

[43] Acknowledgments. This study was supported by funding from the Swiss National Science Foundation (SNSF). We would like to thank the HiRISE and CRISM teams for supplying the data sets we used in this study. We would like to thank Mikki Osterloo and Tim Haltigin for reviewing the paper and their helpful comments and suggestions, which greatly improved it.

\section{References}

Aydin, A., and J. M. DeGraff (1988), Evolution of polygonal fracture patterns in lava flows, Science, 239, 471-476.

Bibring, J.-P., et al. (2004), OMEGA: Observatoire pour la Minéralogie, l'Eau, les Glaces et l'Activité, Eur. Space Agency Spec. Publ., ESA SP-1240, 37-49.

Bibring, J.-P., et al. (2006), Global mineralogical and aqueous Mars history derived from OMEGA/Mars Express data, Science, 312, 400-404, doi:10.1126/science.1122659.

Boynton, W. V., et al. (2007), Concentration of $\mathrm{H}, \mathrm{Si}, \mathrm{Cl}, \mathrm{K}, \mathrm{Fe}$, and Th in the low- and mid-latitude regions of Mars, J. Geophys. Res., 112, E12S99, doi:10.1029/2007JE002887.

Carr, M. H. (1995), The Martian drainage system and the origin of valley networks and fretted channels, J. Geophys. Res., 100(E4), 7479-7507, doi: $10.1029 / 95 J E 00260$.

Carr, M. H. (1996), Water on Mars, Oxford University Press, New York, pp. 229.

Carr, M., and J. W. Head (2010), Geologic history of Mars, Earth Planet. Sci. Lett., 294, 185-203, doi:10.1016/j.epsl.2009.06.042.

Carter, J., F. Poulet, J.-P. Bibring, and S. Murchie (2010), Detection of hydrated silicates in crustal outcrops in the northern plains of Mars, Science, 328, 1682-1686.

Christensen, P. R., et al. (2001), Mars Global Surveyor Thermal Emission Spectrometer experiment: Investigation description and surface science results, J. Geophys. Res., 106(E10), 23,823-23,871, doi:10.1029/ 2000JE001370.

Christensen, P. R., et al. (2004), The Thermal Emission Imaging System (THEMIS) for the Mars 2001 Odyssey mission, Space Sci. Rev., 110, $85-130$.

Ehlmann, B. L., et al. (2008), Orbital identification of carbonate-bearing rocks on Mars, Science, 322, 1828-1832.

Ehlmann, B. L., et al. (2009), Identification of hydrated silicate minerals on Mars using MRO-CRISM: Geologic context near Nili Fossae and implications for aqueous alteration, J. Geophys. Res., 114, E00D08, doi:10.1029/ 2009JE003339.

Ehlmann, B. L., J. F. Mustard, S. L. Murchie, J.-P. Bibring, A. Meunier, A. A. Fraeman, and Y. Langevin (2011), Subsurface water and clay mineral formation during the early history of Mars, Nature, 479, 53-60.

El Maarry, M. R., W. J. Markiewicz, M. T. Mellon, W. Goetz, J. M. Dohm, and A. Pack (2010), Crater floor polygons: Desiccation patterns of ancient lakes on Mars?, J. Geophys. Res., 115, E10006, doi:10.1029/2010JE003609.

El Maarry, M. R., J. Kodikara, S. Wijessoriya, W. J. Markiewicz, and N. Thomas (2012a), Desiccation mechanism for formation of giant polygons on Earth and intermediate-sized polygons on Mars: Results from a pre-fracture model, Earth \& Planet. Sci. Lett., 323, 19-26.

El Maarry, M. R., W. J. Markiewicz, J. Kodikara, E. Heggy, and N. Thomas (2012b), Towards a better understanding of desiccation processes on Mars and its implication to Martian hydrology: Numerical modelling, global mapping, and field studies, European Planetary Science Congress, Abstract id:EPSC2012-168.
Fairén, A. G. (2010), A cold and wet Mars, Icarus, 208, 165-175, doi:10.1016/j.icarus.2010.01.006.

Fassett, C. I., and J. W. Head (2008), The timing of Martian valley network activity: Constraints from buffered crater counting, Icarus, 195, 61-89.

Glotch, T. D., J. L. Bandfield, L. L. Tornabene, H. B. Jensen, and F. P. Seelos (2010), Distribution and formation of chlorides and phyllosilicates in Terra Sirenum, Mars, Geophys. Res. Lett., 37, L16202, doi:10.1029/ 2010 GL044557.

Glotch, T. D., J. L. Bandfield, M. J. Wolff, J. A. Arnold (2013), Chloride salt deposits on Mars-No longer "putative", 44th Lunar and Planetary Science Conference,. Abstract No. 1719, p. 1549

Gorelick, N. S., et al. (2003), JMARS: A multimission data fusion application, $34^{\text {th }}$ Lunar Planet. Sci., Abstract N. 2057.

Greeley, R., and D. A. Crown (1990), Volcanic geology of Tyrrhena Patera, Mars, J. Geophys. Res., 95(B5), 7133-7149, doi:10.1029/ JB095iB05p07133.

Grossenbacher, K. A., and S. M. McDuffie (1995), Conductive cooling of lava: Columnar joint diameter and stria width as functions of cooling rate and thermal gradient, J. Volcanol. Geotherm. Res., 69, 95-103.

Harris, R. C. (2004), Giant desiccation cracks in Arizona, Arizona Geology, vol. 34, n.2.

Hartmann, W. K., and G. Neukum (2001), Cratering chronology and the evolution of Mars, Space Sci. Rev., 96, 165-194.

Howard, A. D., J. M. Moore, and R. P. Irwin, III (2005), An intense terminal epoch of widespread fluvial activity on early Mars: 1. Valley network incision and associated deposits, J. Geophys. Res., 110, E12S14, doi:10.1029/2005JE002459.

Hynek, B. M., M. Beach, and M. R. T. Hoke (2010), Updated global map of Martian valley networks and implications for climate and hydrologic processes, J. Geophys. Res., 115, E09008, doi:10.1029/2009JE003548.

Irwin, R. P., III, R. A. Craddock, A. D. Howard, and H. L. Flemming (2011), Topographic influences on development of Martian valley networks, J. Geophys. Res., 116, E02005, doi:10.1029/2010JE003620.

Jensen, H. B., and T. D. Glotch (2011), Investigation of the near-infrared spectral character of putative Martian chloride deposits, J. Geophys. Res., 116, E00J03, doi:10.1029/2011JE003887.

Langevin, Y., F. Poulet, J.-P. Bibring, and B. Gondet (2005), Sulfates in the north polar region of Mars detected by OMEGA/Mars Express, Science, $307(5715), 1584-1586$

Lawrence, A. H., J. P. Smoot, and H. P. Eugster (1978), Saline lakes and their deposits: A sedimentological approach, Spec. Publs. Int. Ass. Sediment., 2, 7-41.

Loope, D. B., and Z. E. Haverland (1988), Giant desiccation fissures filled with calcareous eolian sand, Hermosa Formation (Pennsylvanian), southern Utah, Sediment. Geol., 56, 403-413.

Lyons, W. B., et al. (1998), Geochemical linkages among glaciers, streams and lakes within the Taylor Valley, Antarctica, Am. Geophys. Union, 77-92.

Mangold, N. (2005), High latitude patterned grounds on Mars: Classification, distribution and climatic control, Icarus, 174, 336-359, doi:10.1016 j.icarus.2004.07.030.

Mangold, N., A. Gendrin, B. Gondet, S. LeMouelic, C. Quantin, V. Ansan, J.-P. Bibring, Y. Langevin, P. Masson, and G. Neukum (2008), Spectral and geological study of the sulfate-rich region of West Candor Chasma, Mars, Icarus, 194(2), 519-543.

McEwen, A. S., et al. (2007), Mars Reconnaissance Orbiter's High Resolution Imaging Science Experiment (HiRISE), J. Geophys. Res., 112, E05S02, doi:10.1029/2005JE002605.

McGill, G. E., and L. S. Hills (1992), Origin of giant Martian polygons, J. Geophys. Res., 97(E2), 2633-2647, doi:10.1029/91JE02863.

McKeown, N. K., J. L. Bishop, and E. A. Silver (2013), Variability of rock texture and morphology correlated with the clay-bearing units at Mawrth Vallis, Mars, J. Geophys. Res. Planets, 118, 1245-1256, doi:10.1002/ jgre.20096.

Mellon, M. T. (1997), Small-scale polygonal features on Mars: Seasonal thermal contraction cracks in permafrost, J. Geophys. Res., 102(E11), 25,617-25,628, doi:10.1029/97JE02582.

Mellon, M. T., R. E. Arvidson, J. J. Marlow, R. J. Phillips, and E. Asphaug (2008), Periglacial landforms at the Phoenix landing site and the northern plains of Mars, J. Geophys. Res., 113, E00A23, doi:10.1029/2007JE003039.

Morgan, F., et al. (2011), Improved algorithm for CRISM volcano scan atmospheric correction, $42^{\text {nd }}$ Lunar \& Planet. Sci. Conf. Abstract N. 2543. Mouginis-Mark, P. J. (1985), Volcano/ground ice interactions in Elysium Planitia, Mars, Icarus, 64, doi:10.1016/0019-1035(85)90090-9.

Mouginis-Mark, P. J., L. Wilson, and J. W. Head, III (1982), Explosive volcanism on Hecates Tholus, Mars: Investigation of eruption conditions, J. Geophys. Res., 87(B12), 9890-9904, doi:10.1029/JB087iB12p09890.

Murchie, S., et al. (2007), Compact Reconnaissance Imaging Spectrometer for Mars (CRISM) on Mars Reconnaissance Orbiter (MRO), J. Geophys. Res., 112, E05S03, doi:10.1029/2006JE002682. 


\section{EL-MAARRY ET AL.: CRACKING IN CHLORIDE-BEARING TERRAINS}

Murchie, S. L., et al. (2009), A synthesis of Martian aqueous mineralogy after 1 Mars year of observations from the Mars Reconnaissance Orbiter, J. Geophys. Res., 114, E00D06, doi:10.1029/2009JE003342.

Mustard, J. F., et al. (2008), Hydrated silicate minerals on Mars observed by the Mars Reconnaissance Orbiter CRISM instrument, Nature, 454, 305-309.

Neal, J. T., A. M. Langer, and P. F. Kerr (1968), Giant desiccation polygons of Great Basin Playas, Geol. Soc. Am. Bull., 79, 69-90.

Osterloo, M. M., et al. (2008), Chloride-bearing materials in the southern highlands of Mars, Science, 319, 1651-1654, doi:10.1126/science.1150690.

Osterloo, M. M., F. S. Anderson, V. E. Hamilton, and B. M. Hynek (2010), Geologic context of proposed chloride-bearing materials on Mars, J. Geophys. Res., 115, E10012, doi:10.1029/2010JE003613.

Pechmann, J. C. (1980), The origin of polygonal troughs on the northern plains of Mars, Icarus, 42, 185-210.

Poulet, F., J.-P. Bibring, J. F. Mustard, A. Gendrin, N. Mangold, Y. Langevin, R. E. Arvidson, B. Gondet, C. Gomez, and the OMEGA Team (2005), Phyllosilicates on Mars and implications for early Martian climate, Nature, 438, 623-627.

Robinson, M. S., P. J. Mouginis-Mark, J. R. Zimbelman, S. S. C. Wu, K. K. Ablin, and A. E. Howington-Kraus (1993), Chronology, eruption duration, and atmospheric contribution of the Martian volcano Apollinaris Patera, Icarus, 104, 301-323.
Ruesch, O., F. Poulet, M. Vincendon, J.-P. Bibring, J. Carter, G. Erkeling, B. Gondet, H. Hiesinger, A. Ody, and D. Reiss (2012), Compositional investigation of the proposed chloride-bearing materials on Mars using near-infrared orbital data from OMEGA/MEx, J. Geophys. Res., 117, E00J13, doi:10.1029/2012JE004108.

Seibert, N. M., and J. S. Kargel (2001), Small-scale Martian polygonal terrain: Implications for liquid surface water, Geophys. Res. Lett., 28 , 899-902.

Shaw, P. A., and R. G. Bryant (2011), Playas, pans and salt lakes, Chapter 15, in Arid Zone Geomorphology: Process, Form and Change in Drylands, edited by D. S. G. Thomas, pp. 373-401, John Wiley \& Sons, Ltd, Chichester.

Shaw, P. A., and D. S. G. Thomas (1997), Playas, pans and salt lakes, Chapter 14, in Arid Zone Geomorphology: Process, Form and Change in Drylands, edited by D. S. G. Thomas, pp. 293-318, John Wiley \& Sons, Ltd, Chichester.

Tanaka, K. L. (1986), The stratigraphy of Mars, J. Geophys. Res., 91(B13), E139-E158, doi:10.1029/JB091iB13p0E139.

Velde, B. (2010), Origin and Mineralogy of Clays: Clays and the Environment, pp. 329, Springer-Verlag, Berlin.

Wray, J. J., S. L. Murchie, S. W. Squyres, F. P. Seelos, and L. L. Tornabene (2009), Diverse aqueous environments on ancient Mars revealed in the southern highlands, Geology, 37, 1043-1046. 